\title{
CARBON TAX AND ENERGY INTENSITY: ASSESSING THE CHANNELS OF IMPACT USING UK MICRODATA
}

\author{
Morakinyo O. Adetutu, Business School, Nottingham Trent University Morakinyo.Adetutu@ntu.ac.uk Tel:+447584662269 \\ Kayode A. Odusanya, School of Business and Economics, Loughborough University, kayode.odusanya @ntu.ac.uk \\ Thomas Weyman-Jones, School of Business and Economics, Loughborough University, T.G.Weyman-jones@lboro.ac.uk
}

\section{Overview}

Achieving the much-needed global emissions reduction will require significant emissions abatement in the production technologies of manufacturing plants because manufacturing is a major contributor to worldwide pollution- it accounts for around $20 \%$ of global greenhouse gas (GHG) emissions (See IEA, 2010, IPCC, 2014). Similarly, it accounted for around $17 \%$ of UK GHG emissions in 2015, mainly dominated by carbon dioxide (CO2) emissions (MacCarthy et al., 2016). However, considering that manufacturing output is largely tradable, there are valid concerns that policy instruments aimed at curbing industrial emissions could harm international competitiveness, as well as result in job losses and plant closures (Martin et al., 2014). This dilemma or trade-off between emissions reduction and competitiveness underscores the preference of economists for market-based policy instruments (e.g. Pigouvian tax) in the textbook approach for designing optimal climate change policies.

A sparse body of literature (e.g. Bjorner and Jensen, 2002; Floros and Vlachou, 2005; Martin et al., 2014) provides empirical evidence on the negative impact of carbon taxes on industrial energy use or pollution. While this negative relationship is well-established, the existing literature is unable to shed much light on the channels through which a moderate carbon tax leads to reductions in energy intensity. As a consequence, important open questions remain about the behavioral components that drive or dominate firm energy intensity reductions: how do firms achieve energy intensity gains when they are faced by a moderate carbon tax liability? How do industrial climate policies place binding constraints on firm behavior? Are the carbon tax-induced changes in actual firm behavior consistent with predicted policy outcomes? In practice, there exists a range of firm responses to a moderate tax on carbon. For instance, firms may adjust the input mix within their production technologies in response to changes in the relative price of energy arising from a carbon tax liability. Secondly, they might install new capital with lower energy-using technologies. A third alternative is that firms may pursue low carbon innovation efforts or knowledge through R\&D investments that deliver efficiency improvements in existing production technologies. Furthermore, it is also possible that some firms may choose to exploit scale economies in order to absorb the tax-induced shocks to energy costs.

In this study, we unbundle the aforementioned firm responses/components of energy intensity reductions arising from the UK climate change levy (CCL). This study is important for at least two reasons. First, it allows for a comprehensive evaluation of carbon tax policy by presenting a more complete picture of its effects on energy intensity adjustments within firm production technologies, which might be impossible in a typical impact study. Secondly, because most market based environmental policy instruments are usually geared towards stimulating energy efficiency, this study allows us to assess the implicit assumption or widely held notion that climate policy instruments lower energy intensity through energy efficiency improvement. This assumption or policy approach requires some scrutiny. If energy efficiency is a small component of overall energy intensity reduction, it raises great potential for policy failure in cases where huge public investments are directed towards stimulating efficiency improvements in the face of other dominant behavioural components. Therefore, gaps in knowledge about firm responses to climate policy instruments can be costly.

\section{Methods}

We construct a plant-level panel data set covering 493 manufacturing plants over the period 2001-2006. We mainly draw our data from two restricted-use UK production surveys: the Quarterly Fuels Inquiry (QFI) and the Annual Respondents Database (ARD). In addition, we employ a two-stage econometric approach to provide the first comprehensive analysis of the five components of industrial energy intensity gain (EIG) due to the UK CCL. In the first stage of our research design, unbundle energy intensity responses by proposing an energy intensity decomposition based on a stochastic energy expenditure frontier. In the second stage, we estimate the impact of the carbon tax on the EIG components using an instrumental variables (IV) approach that addresses the endogeneity of the UK CCL rules. Because our model also allows for the isolation of firm-specific responses to a moderate carbon 
tax, it fits the fact or reality that firms possess heterogeneous production technologies, and their profit maximizing responses to an exogenous policy shock would vary accordingly.

\section{Results}

While it is often simplistically assumed that changes in energy intensity of economic activity are synonymous with changes in energy efficiency; we find that this is not the case as the energy efficiency change derived from our specified stochastic energy expenditure frontier is a relatively small part of the overall changes in energy intensity. The chief impact of the climate change levy is on the adjustment between energy and the use of other inputs and on the rate of technological change. Both results lead us to conclude that firm investments and R\&D expenditure are important channels of the impact of environmental policy on reducing the ratio of energy usage to economic activity levels. These findings are robust to heterogeneity and endogeneity concerns. Even when we re-estimate our EIG regressions using (i) a balanced data sample (ii) alternative sub-samples and (iii) alternative instrumens; our main findings are qualitatively intact.

\section{Conclusions}

A strong policy implication follows from our findings. Much of the discussion of energy and environmental policy equates the long term overall objective of decreasing the energy intensity of production - the de-carbonization agenda - with a supposed unexploited reservoir of energy efficiency. Our findings cast doubt on the idea that there is a large reservoir of energy efficiency changes or 'unnoticed dollar bills on the sidewalk' waiting to be picked up if only firms and consumers made the effort. This notion still characterizes much of the popular debate on decarbonizing the economy. Our findings suggest that "massive potential gains" in energy intensity are not readily available without effortful policy innovation, and policy is better directed at the everyday decisions to invest in new technologies and to innovate in the relative use of different inputs. Rather than targeting hypothetical and ephemeral energy efficiency improvements, policy may be more effective if it is directed towards improvements in the overall allocation of resources including the incentivization of investment and R\&D. Certainly the current policy instrument, the climate change levy, works most effectively in this way.

\section{References}

Bjørner, T.B. and Jensen, H.H. (2002). Energy taxes, voluntary agreements and investment subsidies- a micro-panel analysis of the effect on Danish industrial companies'energy demand. Resource and Energy Economics, 24(3), pp.229-249.

Floros, N. and Vlachou, A. (2005). Energy demand and energy-related CO 2 emissions in Greek manufacturing: assessing the impact of a carbon tax. Energy Economics, 27(3), pp.387-413.

IEA, (2010). Energy Technology Perspectives- Scenarios and Strategies to 2050. International Energy Agency, Paris.

IPCC. Climate change (2014). Fifth Assessment Report, Intergovernmental Panel on Climate Change, Geneva, CH, 2014

MacCarthy, J., Murrells, T., Pang, Y., Passant, N., Ramirez Garcia, J., Thistlethwaite, G., Webb, N., Choudrie, S., Forden, S., Gilhespy, S. and Glendining, M. (2016). UK Greenhouse Gas Inventory, 1990 to 2014.

Martin, R., de Preux, L.B., and Wagner, U.J. (2014). The impact of a carbon tax on manufacturing: Evidence from microdata. Journal of Public Economics, 117, pp. 1-14 